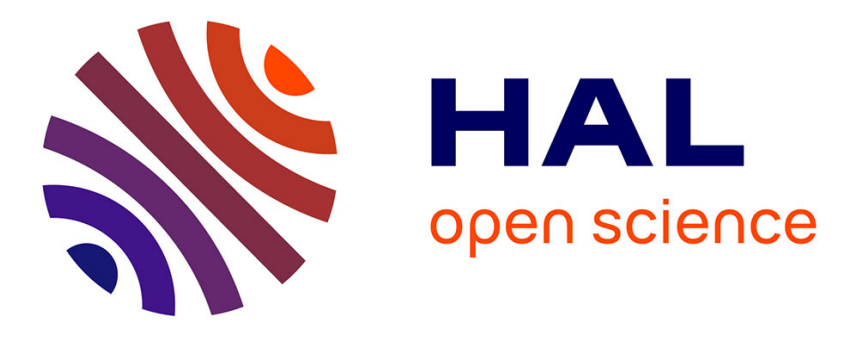

\title{
Characterization of electrooptic polymer applied to microwave sensing
}

Arnaud Gardelein, Sylvain Le Tacon, Eric Tanguy, Nicolas Breuil, Tchanguiz

Razban

\section{- To cite this version:}

Arnaud Gardelein, Sylvain Le Tacon, Eric Tanguy, Nicolas Breuil, Tchanguiz Razban. Characterization of electrooptic polymer applied to microwave sensing. Microwave Photonics, 2006. MWP '06. International Topical Meeting on, Oct 2006, Grenoble, France. pp.1-4, 10.1109/MWP.2006.346571 . hal-00935088

\section{HAL Id: hal-00935088 \\ https://hal.science/hal-00935088}

Submitted on 4 Feb 2014

HAL is a multi-disciplinary open access archive for the deposit and dissemination of scientific research documents, whether they are published or not. The documents may come from teaching and research institutions in France or abroad, or from public or private research centers.
L'archive ouverte pluridisciplinaire HAL, est destinée au dépôt et à la diffusion de documents scientifiques de niveau recherche, publiés ou non, émanant des établissements d'enseignement et de recherche français ou étrangers, des laboratoires publics ou privés. 


\title{
Characterization of electrooptic polymer applied to microwave sensing
}

\author{
Arnaud Gardelein*, Sylvain Le Tacon*, Eric Tanguy*, Nicolas Breuil ${ }^{\dagger}$ and Tchanguiz Razban* \\ ${ }^{*}$ Université de Nantes, Nantes Atlantique Universités, IREENA, EA1770, Polytech-Nantes, \\ rue C. Pauc - Bât. IRESTE BP 50609, Nantes, F-44000 France \\ ${ }^{\dagger}$ Thales Airbone Systems, 2 avenue Gay-Lussac, Elancourt, F-78895 France
}

\begin{abstract}
In this paper we present electrooptic measurement of a crosslinked side chain PGMA/DR1 polymer. Measured values are as high as $11 \mathrm{pm} / \mathrm{V}$ at $1310 \mathrm{~nm}$, we present measurement as a function of incident beam reflexion point and show dependance between the reflexion point location over the sample and the measured electrooptic coefficient. We present low frequency relative dielectric constant using a capacitance measurement method. Using this method, we found a relative permittivity of $4.46 \pm \mathbf{0 . 3 8}$ for our polymer. We present a new electrooptic microwave sensor, where we enhance the electrooptical interaction by increasing the optical path length using a Fabry-Perot cavity and we concentrate the electric field inside our device using a microstrip resonator. Expected interaction enhancement value is expected to be as high $310^{5}$ compared to the simple reflexion case at low frequency.
\end{abstract}

\section{INTRODUCTION}

To transport information at high bit rate over great distances, fiber optic is fully adapted : low cost, low losses. But when comes time to connect each user to the backbone network using fiber to the home (FTTH) technology, cost goes incresingly higher. In fact, a large part of the network's cost comes from the infrastructure deployment to the user, more precisely the last mile.

A relevant approach is microwave communications, through Local Multipoint Distribution Service (LMDS), for data to the user transmission. However, nowadays optoelectronics transmitters have several drawbacks. They are expensive to produce, and present high electrical power consumption. In this paper we present a new device, using a low cost polymer electro-optic antenna.

We describe here the receiving part of the device : the user sends the signal to our optoelectronical transmitter. Then the device has to receive the microwave-carried information, and to convert it directly to optical one. The convertion procedure uses the second order non linear electrooptical effect, where the electrically-induced optical index variation modifies the propagating optical waves speed, resulting in a polarization change. As a first approach, lithium niobate could be used : high electrooptic coefficient, time stability, and electrooptical modulation has been demonstrated up to $40 \mathrm{GHz}[1]$. However, this material presents high dielectric constants $\left(\varepsilon_{r} \approx 43\right.$ and 28 ) and index $(n \approx 2.2)$, and moreover high production cost. The difference between optical index and microwave dielectric constant causes a velocity mismatch between optical and radiofrequency waves, which limits the modulator bandwidth.
Since two last decades, research has focused on new low cost electrooptic performant materials, and organic poled polymers have emerged. Those materials present a low dielectric constant $\left(\varepsilon_{r} \approx 3[2]\right)$ and optical index $(n \approx 1.6)$, reducing the velocity mismatch and then enhancing the modulator bandwidth up to $102 \mathrm{GHz}$ [3], [4]. The main drawback of polymer is stability over time and temperature : electrooptical properties tend to decrease as time goes on. Here we present a stable polymer, a PGMA backbone with a side chain DR1 chromophore. The long term stability is achieved by a epoxide cross-linkable function [5], attached to the backbone. This polymer combinates the well-known PGMA/DR1 electrooptic properties with long-term stability provided by cross-linking. In the following we will present the microwave and electrooptic polymer characterization, compulsory steps for the sensor design. The last section will discuss of the sensor itself.

\section{ELECTROOPTICAL CHARACTERIZATION}

To measure the electrooptical coefficient $r_{33}$, we use the simple reflexion technique proposed by Teng and Man [6], as shown on Fig. 1. The required parameters are the modulation

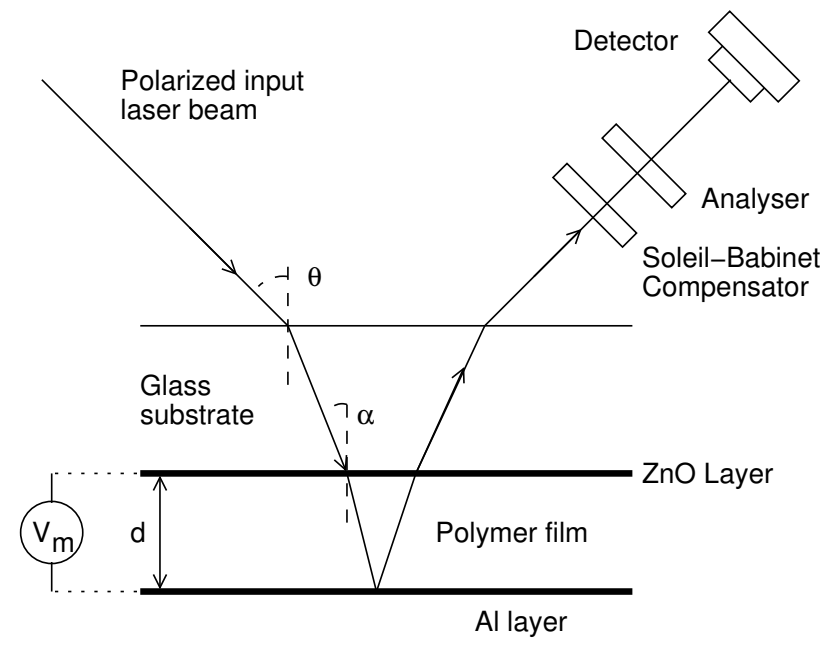

Fig. 1. Electrooptical measurement principle as proposed by Teng and Man.

voltage $V_{m}$ applied across the sample, the polymer's optical index $n$, the intensity measured before the analyser $I_{\max }$, the optical beam modulated intensity $I_{m}$, the incidence angle $\theta$ and the wavelength $\lambda$. From the measurement of those 
parameter, the electrooptical coefficient is deduced using [7]

$$
r_{33}=\frac{3 \lambda}{2 \pi V_{m}} \frac{\sqrt{n^{2}-\sin ^{2} \theta}}{n^{2} \sin ^{2} \theta} \frac{I_{m}}{I_{\max }}
$$

\section{A. Sample preparation}

Samples were prepared using a glass subtrate, first coated with $1-\mu \mathrm{m}$-thick $\mathrm{ZnO}$ as bottom electrode. Then the polymer, dissolved in (1,1,2-Trichloroethane), was spun-cast on the $\mathrm{ZnO}$. The samples were then poled by corona effect, by applying $5 \mathrm{kV}$ over $1 \mathrm{~cm}$ between the pin and the ground electrode and warming the sample up to the glass transition temperature and then cross-linking temperature. Thereafter, the top aluminium electrode was evaporated as a $12 \mathrm{~mm}$ x $15 \mathrm{~mm}$ rectangular surface.

\section{B. Measurement results}

Measurements were made over 3 samples, results are presented table I. We measured $r_{33}$ values as high as $11 \mathrm{pm} / \mathrm{V}$ for sample 2 at $1310 \mathrm{~nm}$. Since measurements were made using a random location over the sample, we obtained the electrooptic coefficient as a function of the measurement location point, where the incident laser beam reflects over the electrode. Results for sample 1 are shown Fig. 2 We find out that the electrooptic coefficient varies from $4 \mathrm{pm} / \mathrm{V}$ to $6 \mathrm{pm} / \mathrm{V}$. The cause of this variation seems to be the corona poling method, where poling effciency depends from the pin-tip placement.

\begin{tabular}{llr}
\hline Sample & Wavelength $(\lambda)$ & EO coefficient $\left(r_{33}\right)$ \\
\hline EO-1 & $1310 \mathrm{~nm}$ & $4.02 \pm 1.18 \mathrm{pm} / \mathrm{V}$ \\
EO-2 & $1310 \mathrm{~nm}$ & $6.96 \pm 1.73 \mathrm{pm} / \mathrm{V}$ \\
EO-3 & $1310 \mathrm{~nm}$ & $2.45 \pm 0.39 \mathrm{pm} / \mathrm{V}$ \\
\hline EO-1 & $1550 \mathrm{~nm}$ & $1.36 \pm 0.33 \mathrm{pm} / \mathrm{V}$ \\
EO-2 & $1550 \mathrm{~nm}$ & $7.97 \pm 1.48 \mathrm{pm} / \mathrm{V}$ \\
EO-3 & $1550 \mathrm{~nm}$ & $2.42 \pm 0.23 \mathrm{pm} / \mathrm{V}$ \\
\hline
\end{tabular}

TABLE I

ELECTROOPTICAL COEFFICIENT MEASUREMENT RESULTS

\section{Dielectric CONSTANT MEASUREMENT}

For the microwave design of the electrooptic antenna, we have to know the relative diectric constant of the polymer. The main constraint for the electric measurement is the thickness of the polymer layer, in a range from 1 to $5 \mu \mathrm{m}$. Thus, we used a capacitance method to measure the dielectric constant. The capacity $C$ of a condensator is a function of the electrodes surface $S$, the space between electrodes, or polymer thickness, $d$ and the dielectric constant $\varepsilon_{r}$ :

$$
C=\varepsilon_{0} \varepsilon_{r} \frac{S}{d}
$$

Measurement of the capacity $C$, the surface $S$ and the thickness $d$ leads to the dielectric constant.

For the experiment, we used samples of 16 aluminium electrodes, 2-mm diameter, evaporated over the polymer layer. The polymer was deposited by spin coating at $4000 \mathrm{rpm}$ during 30 seconds, on an aluminium layer over a glass substrate. The capacity of each condensator was measured at $1 \mathrm{MHz}$ using

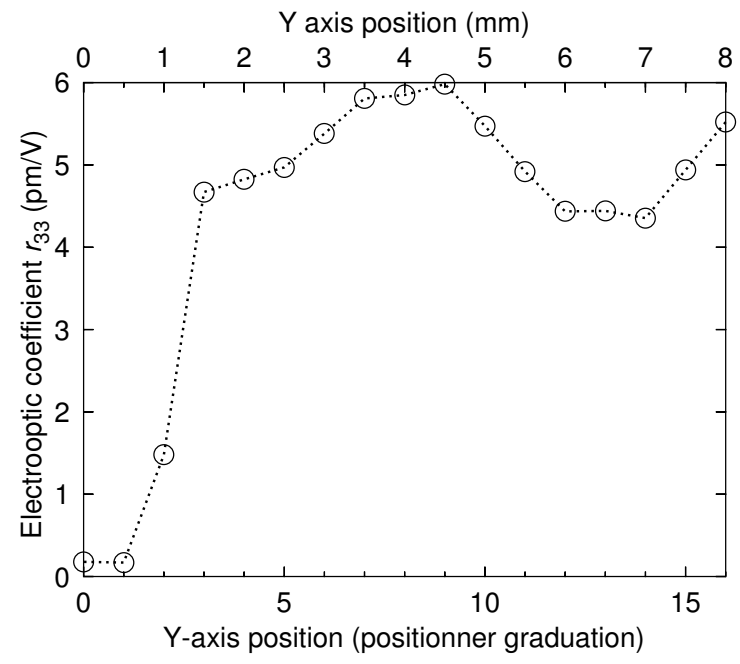

Fig. 2. Electrooptic coefficient as a function of measurement location. The beam is centered along the $x$ direction. On the figure, the bottom electrode, optically used as a mirror layer, starts at $y=1 \mathrm{~mm}$.

impedance/gain-phase HP4149A. Cutting samples deposited in the same conditions leaded to the thickness measurement by SEM. The precision is $\pm 50 \mathrm{~nm}$.

There was 3 samples of 16 condensators, meaning 48 capacity measurements. Capacity measurement results are shown Tab. II. The evaluated thickness is $920 \pm 50 \mathrm{~nm}$. We reported table II the permittivity computed using this value. Therefore, the average permittivity is $\varepsilon_{r}=4.46 \pm 0.38$.

\begin{tabular}{lll}
\hline Sample & Mean capacity & Permittivity \\
\hline ER-1 & $131.8 \pm 1.5 \mathrm{pF}$ & $4.36 \pm 0.30$ \\
ER-2 & $133.7 \pm 1.7 \mathrm{pF}$ & $4.42 \pm 0.31$ \\
ER-3 & $138.9 \pm 1.7 \mathrm{pF}$ & $4.60 \pm 0.32$ \\
\hline \multicolumn{3}{c}{ TABLE II }
\end{tabular}

PER-SAMPLE MEAN CAPACITY AND ESTIMATED PERMITTIVITY.

\section{Electrooptical ANTEnNA}

Considering the simple reflection technique for electrooptic coefficient measurement, the measurement procedure can be done at microwave frequencies. Moreover, instead of electricaly exciting the device with a coaxial cable, one can avoid connexion problem using a free space incident wave. Hence we have an electrooptic antenna.

However, sensitivty can be enhanced by increasing microwave/optical interaction.

\section{A. Optical Fabry-Pérot resonator}

As a first approach, this can be done using the Fabry-Perot effet : the polymer layer may be sandwiched between two mirrors, the top aluminium electrode and a dielectric mirror as shown on Fig. 3. We experimentally measured the reflexion coefficient of aluminium and found a value of $r_{a l}=0.911$ at best for a $1310 \mathrm{~nm}$ wavelength. Using a value of $r_{\text {diel }}=$ 


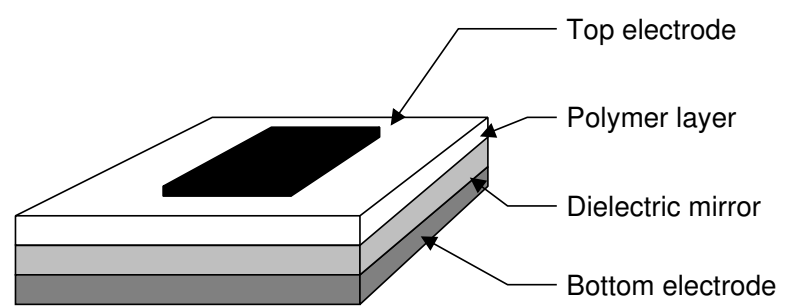

Fig. 3. Structure of the proposed electrooptic microwave sensor. Top electrode, polymer layer and dielectric mirror are considered as a FabryPérot cavity, whereas top electrode, polymer layer and bottom electrode are considered as a microwave resonator.

0.9949 [8], we can compute the photon lifetime $\tau_{p}$ inside the Fabry-Perot cavity [9] :

$$
\tau_{p}=\frac{1}{\alpha_{r}} \quad \text { where } \quad \alpha_{r}=\alpha_{s}+\frac{1}{2 d} \ln \frac{1}{r_{a l}^{2} r_{d i e l}^{2}}
$$

with $\alpha_{r}$ the total optical losses and $\alpha_{s}$ the polymer optical losses, and right hand side second term the reflexion losses. This leads to the mean photon optical path length :

$$
l_{p}=\tau_{p} \frac{c}{n}=\frac{1}{n \alpha_{r}}
$$

Since we expect to increase the path length up to a few tens of microns, as a first approximation we can neglect the polymer optical losses $\alpha_{s}$. With previously mentionned values, we find $l_{p}=15.2 \mu \mathrm{m}$. Comparing this value to the single reflexion case, $l=2 d / \cos \theta=2.82 \mu \mathrm{m}$ where $d=1.2 \mu \mathrm{m}$ and $\theta=35^{\circ}$, the optical patch length is 5.4 times greater.

\section{B. Resonant antenna}

The rectangular aluminium top electrode is modelised at microwave frequencies as a microstrip transmission line, and the open ends as parallel admittances. The patch dimensions are $L \times W$ with a substrate heigh $h$ and a relative permittivity $\varepsilon_{r}$. Using the equivalent slot concept, the real part of the parallel admittance represents mainly the radiation effect of the antenna. According to this model, the unloaded antenna factor of a microstrip antenna is [10] :

$$
Q=\frac{\pi}{2} \frac{Y_{c}}{G_{r}}
$$

Where $G_{r}=2\left(G_{s}+G_{m}\right)$ is the sum of the slots conductances, and $Y_{c}$ the characteristic admittance of the microstrip line. Here, the susbtrate is very thin leading to a $W / h$ ratio of $10^{4}$. Hence, we can consider the effective permittivity and the effective line width defined by Van de Capelle equal to the relative permittivity and the line width respectively. The slot conductance is defined as a function of the normalised slot length $w=k W, k=\frac{2 \pi}{\lambda}$ :

$$
G_{s} \approx \frac{1}{\pi \eta}\left\{w \operatorname{Si}(w)+\frac{\sin w}{w}+\cos w\right\}
$$

the mutual conductance $G_{m}$ between the two slots is given by $G_{m}=F_{g} G_{s}$ with the auxialiary coupling function $F_{g}$ (considering normalised slot width $\ll 1$ ) :

$$
F_{g} \approx J_{0}(l)
$$

where $l=k L$ is the normalised slot space and $J_{0}$ the Bessel function of the first kind. The characteristic admittance $Y_{c}$ is

$$
Y_{c}=\frac{1}{Z_{c}}=\frac{\sqrt{\varepsilon_{r}}}{\eta_{0}} \frac{W}{h}
$$

With $L=15 \mathrm{~mm}, W=12 \mathrm{~mm}, h=1$ micron and $\varepsilon_{r}=$ 3 , at resonant frequency, $G_{r} \approx 1.52 \mathrm{mS}$ and $Y_{c}=55.1 \mathrm{~S}$. The unloaded quality factor is then $Q=56$ 941. This quality factor provides us with the maximum order of magnitude we can expect for the field concentration inside our antenna.

Using the Fabry-Perot effect and the top electrode as a patch antenna, we can then enhance the interaction between optical and microwave signals of a factor up to 300000 .

\section{CONCLUSION}

In this paper we presented the electrooptical polymer synthetised at University of Nantes. The measured electrooptical values are as high as $11 \mathrm{pm} / \mathrm{V}$, but we showed that the values are dependent of the measurement location. We presented the low frequency relative dielectric constant of this polymer of $\varepsilon_{r}=4.46 \pm 0.38$.

We then proposed a new electrooptic antenna principle, where the electrooptical interaction is enhanced by increasing the optical path length using a Fabry-Perot cavity. The electric field is concentred inside the device, using the top electrode as amicrostrip resonator. Expected interaction enhancement is as high as $310^{5}$ compared to the low frequency simple reflexion technique.

\section{ACKNOWLEDGEMENTS}

The authors wish to thank C. Monnereau, A. Scarpaci, E. Blart, F. Odobel from LSO, Nantes for synthetising the polymer, R. Seveno, D. Averty and H. Gundel from IREENA, Nantes for polymer depositing and poling and N. Barreau from LAMP, Nantes for depositing the aluminium layer. Cookson Electronics, Cholet, France which realized the electrode evaporation masks is thereby granted. Paul Molina, IRCCyN, is acknowledged for the building of main mechanichal pieces for the electrooptic characterization experiment. Finally the french region of "Pays de Loire" is granted for funding this work.

\section{REFERENCES}

[1] L. Binh, "Lithium niobate optical modulators: Devices and applications," Journal of Crystal Growth, vol. 288, pp. 180-7, Feb. 2006.

[2] G. Subramanyam, P. Mathala, C. Chevalier, A. Davis, P. Yaney, and J. Grote, "Microwave characterization of electrooptics polymers," in Material Research Society Symposium Proceedings, vol. 734, pp. 249 254, 2003.

[3] M. G. Kuzyk and C. W. Dirk, Characterization techniques and tabulations for organic nonlinear optical materials. Optical Engineering S., v. 60, Marcel Dekker Inc, may 1998. ISSN 0-8247-9968-2.

[4] D. H. Chang, H. Erlig, M.-C. Oh, C. Zhang, W. H. Steier, L. R. Dalton, and H. R. Fetterman, "Time stretching of 102-ghz millimeter waves using novel 1.55-um polymer electrooptic modulator," IEEE photonics technology letters, vol. 12, pp. 537-9, mai 2000.

[5] F. Foll, D. Bosc, J. Liang, A. Rousseau, and B. Boutevin, "Preparation of curable polymers for use in nonlinear optical devices." European patent, 1995. 
[6] C. C. Teng and H. T. Man, "Simple reflection technique for measuring the electro-optic coefficient of poled polymers," Applied Physics Letter, vol. 58, pp. 1734-1736, 1990.

[7] M. A. Mortazavi, A. knoesen, S. T. Kowel, R. A. Henry, J. M. Hoover, and G. A. Lindsay, "Second-order nonlinear optical properties of poled coumaromethacrylate copolymers," Applied Physics B, vol. 53, pp. 287295, 1991.

[8] G. Gaborit, Caractérisation de champs électriques hyperfréquences par capteur électrooptique vectoriel fibré. $\mathrm{PhD}$ thesis, Université de Savoie, novembre 2005.

[9] B. E. A. Saleh and M. C. Teich, Fundamentals of Photonics. Wiley, August 1991.

[10] A. V. de Capelle, Transmission-line model for rectangular microstrip antennas, vol. 1 of Handbook of microstrip antennas, ch. 10, pp. 527578. Peter Peregrinus, 1989. 